\title{
Fat intake: implications of changes in distribution for setting dietary goals in the UK
}

Jane Pryer, Eric Brunner, Michael Marmot

\begin{abstract}
Study objective - To examine (a) changes in the shape of the distribution of dietary fat intake as the mean dietary fat intake of the population shifts and (b) implications for setting national dietary goals.
\end{abstract}

Design - Data on the percentage of energy from total fat, saturates, monounsaturates, polyunsaturates, and the $P: S$ ratio were analysed for two dietary intervention trials and six cross sectional dietary surveys. The nutrient distributions from each study were described in terms of the mean, standard deviation (SD), coefficient of variation (CV), and skewness statistic. For the intervention trials statistical parameters were compared for groups who received and did not receive dietary advice. For the cross sectional studies, statistical parameters were compared across groups with different levels of mean fat intake. The implications of the results for setting dietary goals were considered using statistical models.

Main results - For most fat fractions there was a positive association between the mean and the SD, and an inverse association between the mean and the $C V$, indicating that as the mean shifts upwards the SD increases but not in proportion to the mean. This is intermediate between a constant $S D$ and a constant $C V$ model. For a population nutrient goal of a maximum of $15 \%$ saturates, the estimated population mean for British women would be $8.4 \%$ using the constant SD model and $10.8 \%$ using the constant $\mathrm{CV}$ model. For saturates and the P:S ratio, a lower mean intake was associated with a greater positive skew in the distribution of reported intakes. For saturates, this is consistent with a group of high fat consumers who fail to reduce their intake as the population mean shifts downwards: a "rearguard effect". Findings for the P:S ratio are consistent with a group of consumers who produced a strong positive skew at low mean intakes, which reduced in size as the mean population intake increases: a "vanguard effect".

Conclusions - These findings provide evidence that the distribution of fat intake may change with the mean to a degree that the setting and monitoring of nutritional goals may need to take account of changes in variance and shape of the intake distribution.

( $($ Epidemiol Community Health 1994;48:543-548)
In 1984, the Committee on Medical Aspects of Food Policy (COMA) Panel on Diet and Cardiovascular Disease recommended a reduction in total fat and saturated and trans fat intakes in the UK population to yield $35 \%$ and $15 \%$ respectively of energy. ${ }^{1}$ These recommendations have been widely interpreted as mean population dietary goals. ${ }^{2}$ COMA, however, recommended that individuals whose intakes of total fat and saturated and trans fat were above $35 \%$ and $15 \%$ respectively of food energy, should reduce these to the recommended level: this suggests that the recommendations were maxima, not means.

A reduction in the population mean dietary fat intake could theoretically be accompanied by a number of different distributions of intake: (1) The fat intake distribution might stay approximately normal as mean intake decreased, retaining the breadth of the intake range (a constant standard deviation (SD) model);

(2) The distribution might remain normal, but with a narrowing of the range (a constant coefficient of variation (CV) model);

(3) If a section of the population whose intakes were already at the lower end of the distribution made the greatest changes and reduced their intakes still further, a distribution skewed to the left could be obtained;

(4) If a section of the population whose intakes were located at the upper end of the distribution did not reduce their intakes, a distribution skewed to the right could be obtained.

The first of these models, the constant SD model (model 1) is shown in figure 1. The three values chosen for the mean total fat intake as a percentage of food energy are: the 1986-87 UK mean for adult men of $40 \cdot 4 \%,{ }^{3}$ a mean of $35 \%$, and the mean of $25.8 \%$ required to place $95 \%$ of the population below the COMA recommendation of $35 \%$.

Figure 2 illustrates the same example using a constant $\mathrm{CV}$ model (model 2). Under these assumptions, the mean intake required to place $95 \%$ of the population below $35 \%$ of food energy from total fat is $28.5 \%$, compared with $25.8 \%$ under the first model. Under models 3 and 4 described above, the expected mean would be different again.

Central, therefore, to the setting and monitoring of the implementation of dietary goals is an understanding of what happens to the population distribution of fat intake as the mean shifts. The question of the shape of the distribution of fat intake as the mean population intake shifts was raised in the report by the National Advisory Committee on Nutrition Education (NACNE), ${ }^{4}$ in which a constant SD model was assumed. In the World Health Organisation (WHO) report Diet, Nutrition and 


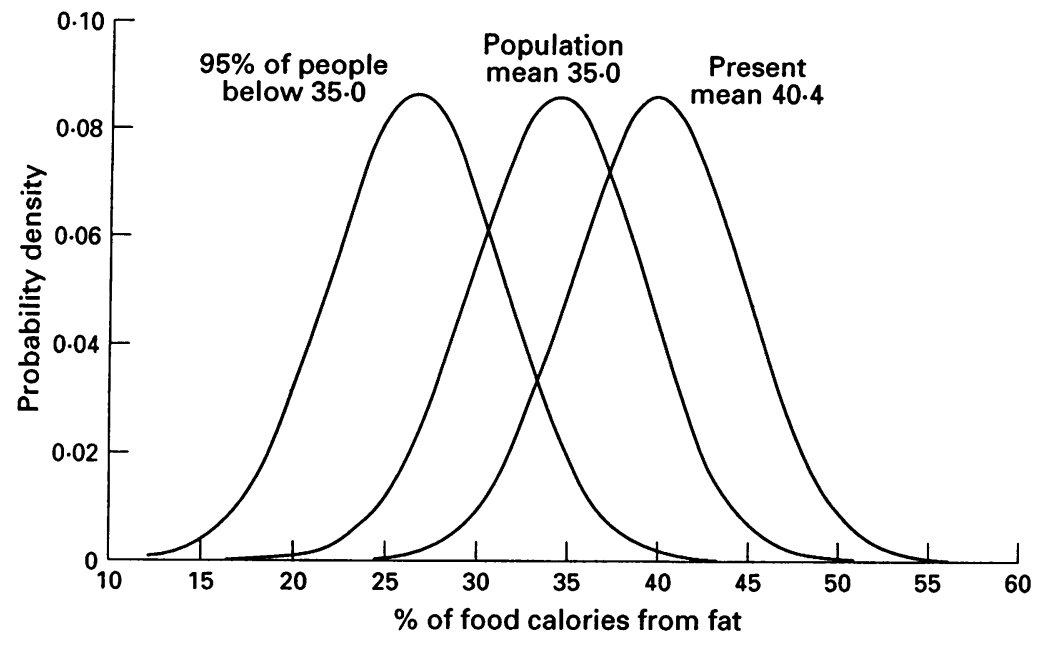

Figure 1. Distribution of fat intakes - constant standard deviation model.

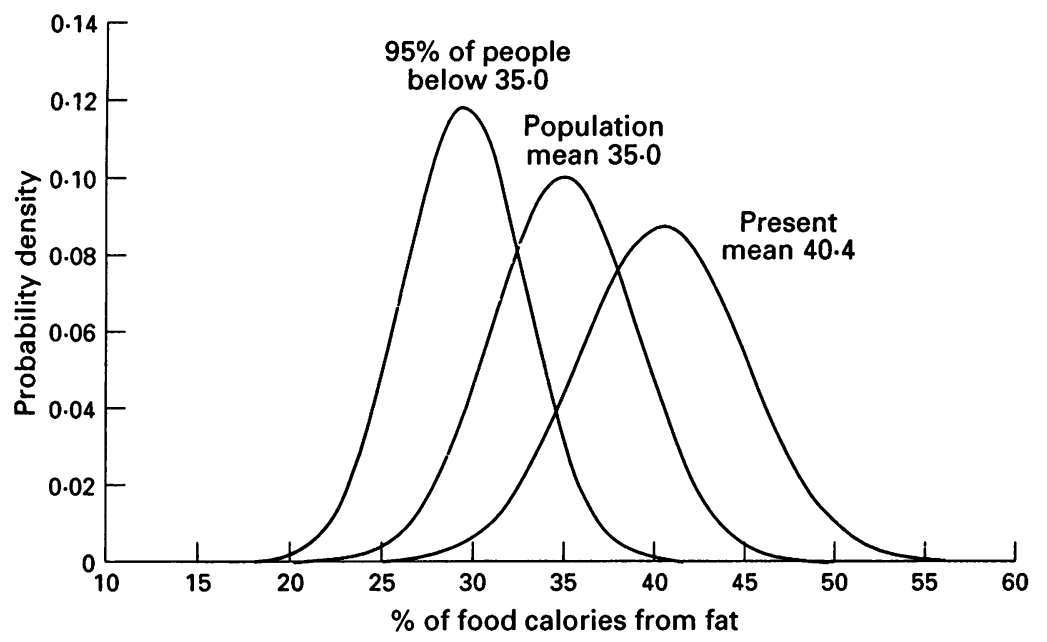

Figure 2. Distribution of fat intakes - constant coefficient of variation model.

the Prevention of Chronic Disease $5^{5}$ a constant SD model was explicitly adopted in setting international population dietary goals. ${ }^{56}$ However, as the United States National Research Council has commented in its report Diet and Health, little is known about the variation of nutrient intake within populations, even on a cross sectional basis.

The identification of the pattern of a population's dietary behaviour is important if dietary goals are to be defined in terms of the extremes of intake as well as the mean. ${ }^{8}$ To date, the question of the change in shape of the distribution of nutrient intake as the population mean shifts has not been examined empirically.

In this paper, we report on analyses using available UK dietary survey data to examine how the population distribution of fat intake changes as the mean population intake shifts.

\section{Methods}

The ideal dataset required to address the issue of changes in the shape of the distribution of fat intake as the population mean shifts would either be a randomly selected cohort study or nationally representative cross sectional samples in which diet was recorded with precision over at least two points in time. Such a dataset could not be identified by examination of Nutrition Abstracts and Reviews since the 1970 s, or from personal communication with nutritionists in the UK, Europe, and the USA. Several datasets and different analytical approaches were therefore adopted. Only studies which use the seven day weighed inventory method were considered suitable for a study of nutrient intake distributions. ${ }^{9}$

\section{DATASETS}

Datasets used included:

Dietary intervention trials

The Diet and Reinfarction Trial (DART) ${ }^{10-12}$ and the British Dietetic Association (BDA) Community Nutrition Nutritional Guidelines Project $^{12}$ (table 1) were included. Both trials consisted of highly motivated individuals.

DART is a randomised controlled trial designed to examine the effect of dietary advice in the secondary prevention of myocardial infarction. The trial used a factorial design to

Table 1 Data sources

\begin{tabular}{|c|c|c|c|c|c|c|}
\hline Study & $\begin{array}{l}\text { Fieldwork } \\
\text { date }\end{array}$ & Sample size & $\begin{array}{l}\text { Demographic } \\
\text { characteristics }\end{array}$ & Sample selection & $\begin{array}{c}\text { Response rate } \\
(\%)\end{array}$ & Reference nos \\
\hline \multirow{2}{*}{$\begin{array}{l}\text { Dietary interventions } \\
\text { BDA Nutrition Guidelines } \\
\text { Project } \\
\text { DART }\end{array}$} & $1984-85$ & \multirow{2}{*}{$\begin{array}{l}\text { Round 1: } 472 \\
\text { Round 2: } 354 \\
2033\end{array}$} & \multirow{2}{*}{$\begin{array}{l}\text { Men and women, } \\
20-40 \text { y } \\
\text { Men, } 30-69 \text { y }\end{array}$} & \multirow{2}{*}{$\begin{array}{l}\text { Volunteer dietitians and adult } \\
\text { members of their households } \\
4371 \text { men attending } 21 \text { hospitals } \\
\text { in Wales after myocardial } \\
\text { infarction }\end{array}$} & \multirow{2}{*}{$\begin{array}{c}\text { Round 1: } 87 \\
\text { Round 2: } 80 \\
46 \cdot 5\end{array}$} & 12 \\
\hline & & & & & & $9,10,11$ \\
\hline $\begin{array}{l}\text { Cross sectional surveys } \\
\text { Dietary and Nutritional } \\
\text { Survey of British Adults }\end{array}$ & $1986-87$ & 2197 & $\begin{array}{l}\text { Men and women, } \\
16-64 \text { y }\end{array}$ & $\begin{array}{l}\text { National representative sample of } \\
\text { men and women living in private } \\
\text { households in UK }\end{array}$ & 70 & 3 \\
\hline $\begin{array}{l}\text { Diet, Lifestyle and Health } \\
\text { in Northern Ireland }\end{array}$ & $1986-87$ & 592 & $\begin{array}{l}\text { Men and women, } \\
16-64 \text { y }\end{array}$ & $\begin{array}{l}\text { National representative sample of } \\
\text { men and women living in private } \\
\text { households in Northern Ireland }\end{array}$ & $74 \cdot 3$ & 13 \\
\hline $\begin{array}{l}\text { Speedwell Heart Disease } \\
\text { Study }\end{array}$ & 1986 & 93 & Men, $45-59 y$ & $\begin{array}{l}\text { Random sample of men registered } \\
\text { with } 16 \mathrm{GPs} \text { in east Bristol }\end{array}$ & 89 & 18 \\
\hline $\begin{array}{l}\text { Caerphilly Heart Disease } \\
\text { Study }\end{array}$ & $1980-83$ & 650 & Men, 45-59y & $\begin{array}{l}\text { Systematic }(3 \text { in } 10) \text { sample of all } \\
\text { men selected from the electorial } \\
\text { register in Caerphilly and } 5 \\
\text { villages }\end{array}$ & 87 & 17 \\
\hline $\begin{array}{l}\text { North Edinburgh, West } \\
\text { Fife CHD Study }\end{array}$ & $1980-82$ & 164 & Men, 45-54 y & $\begin{array}{l}\text { Random sample of men registered } \\
\text { with GPs in North Edinburgh and } \\
\text { West Fife }\end{array}$ & $68 \cdot 5$ & 15 \\
\hline $\begin{array}{l}\text { Edinburgh-Stockholm } \\
\text { Study }\end{array}$ & 1976 & 97 & Men, $40 y$ & $\begin{array}{l}\text { Random sample selected from } \\
\text { General Register Office }\end{array}$ & 90 & 15 \\
\hline
\end{tabular}

BDA $=$ British Dietetic Association $;$ DART $=$ Diet and Reinfarction Trial 
examine the effects of three dietary aims (decreased fat intake, increased fatty fish intake, and increased cereal intake) alone and in combination. ${ }^{12}$ Altogether 4371 men aged 30-69 years who had recently suffered a myocardial infarction were identified, 2033 of whom entered the trial. Exclusions from the trial included those who were already eating (or intended to eat) a diet which incorporated one or more of the three dietary aims $(23.9 \%)$ and those who had an aversion to one of the dietary regimens or who were judged unsuitable for other reasons $(2 \cdot 6 \%)$. Six months into the trial, a seven day weighed inventory was conducted on a random subsample of approximately $25 \%$ of participants; 247 had received dietary fat advice and 212 had not.

The BDA Community Nutritional Guidelines Project was set up to assess whether a motivated group of individuals could achieve dietary goals related to long term NACNE recommendations. ${ }^{4}$ The sample comprised volunteer dietitians and adult members of their households. Firstly, participants followed their usual diet and completed a seven day weighed inventory. Those who did not achieve the dietary goals in round one were asked to make further attempts to do so and recorded a further seven days of weighed dietary intake (round two). Rounds one and two data have been analysed here for all participants who completed both surveys.

Cross sectional surveys

Six cross sectional surveys conducted in the UK between 1976 and 1987 were analysed the Dietary and Nutritional Survey of British Adults (DNSBA); ${ }^{3}$ Diet, Lifestyle and Health in Northern Ireland; ${ }^{14}$ Edinburgh-Stockholm Coronary Heart Disease Study; ${ }^{15} 16$ North Edinburgh-West Fife Coronary Heart Disease Study; ${ }^{17}{ }^{18}$ and the Caerphilly and Speedwell Heart Disease Prospective Cohort Studies ${ }^{18} 19$ (table 1). In contrast to the trials described above, these surveys are more representative of the general adult population.

The cross sectional studies allowed an examination of the distribution of nutrient intake at different mean intakes. Respondents from the $\mathrm{DNSBA}^{3}$ were assigned to one of 12 social class, regional, gender subgroups (see Appendix) for regression analysis.

Data on the percentage of total energy (food plus alcohol) from total fat, saturates, monounsaturates and polyunsaturates, and the P:S ratio from each study were obtained from the study investigators and analysed using $S A S$, version $5 \cdot 18$, on the University of London mainframe. The nutrient intake distributions for each study are described in terms of the mean, $\mathrm{SD}, \mathrm{CV}$ (SD/mean) and skewness statistic.

For the dietary intervention trials the Student's $t$ test was used to test for significant differences between means. The $\mathrm{F}$ test was performed to test for significant differences between standard deviations. A test for differences in skewness was performed using the formula for the standard error of skewness. ${ }^{20}$ No statistical test is available for differences in CVs.
For the cross sectional dietary surveys, regression analyses were undertaken with individual studies or subgroups weighted by sample size to test for associations between the means and the SDs and the means and the skewness statistics (PROC GLM). Regression analyses were not performed to test for associations between the means and the CVs because of the high degree of autocorrelation between these two parameters.

McCance and Widdowson's The Composition of Foods, ${ }^{21}$ with additional supplements, were used in all studies included in this analysis. For comparative purposes, potential sources of systematic error could be present because some researchers used additional nutrient composition data, for example from manufacturers and their own laboratories.

\section{Results}

DIETARY INTERVENTION TRIALS

Summary statistics for the daily intake of total fat, saturates, monounsaturates, and polyunsaturates as a percentage of energy, and the P:S ratio of "non-achievers" in round one of the BDA trial who completed round two and for all round two participants, and for the "fat advice" and "no fat advice" groups of the DART trial are shown in table 2 .

Significant reductions in total fat, saturates, and monounsaturates, and increases in polyunsaturates and the P:S ratio were achieved by participants in round two of the BDA trial, when compared with round one. Similar differences were seen between the "fat advice" and "no fat advice" groups in the DART trial (table 2).

For saturates, both the BDA and the DART trials showed that groups with a lower mean intake, also had a smaller SD (BDA trial, $\mathrm{p}<0.001$ ), a slightly larger $\mathrm{CV}$, and had more positively skewed distributions (DART trial, $\mathrm{p}<0.05)$. These results indicate that as the mean shifts downwards, the SD decreases, but this decrease is not proportional to the mean. The significant increase in positive skewing at lower mean intakes in the DART trial could be consistent with a group of high consumers who fail to reduce their intake as the population mean shifts downwards - a "rearguard effect".

The results for polyunsaturates as a percentage of energy and the $P: S$ ratio were broadly similar to the results for saturates. Groups with a higher mean intake also had a significantly larger SD and a smaller CV. These results again indicate that as the mean shifts upwards, the SD increases, but not in proportion to the mean. Groups with higher mean intakes also had significantly less positively skewed distributions for the P:S ratio in both trials (table 2 ), and for polyunsaturates in the DART trial (table 2). These results could be consistent with a "vanguard effect" - a group of high consumers who produce a rightward skew at low mean intakes, which reduces in size as the population mean increases.

For monounsaturates, both the BDA and 
Table 2 British Dietetic Association (BDA) Nutritional Guidelines Trial and Diet and Reinfarction Trial (DART)

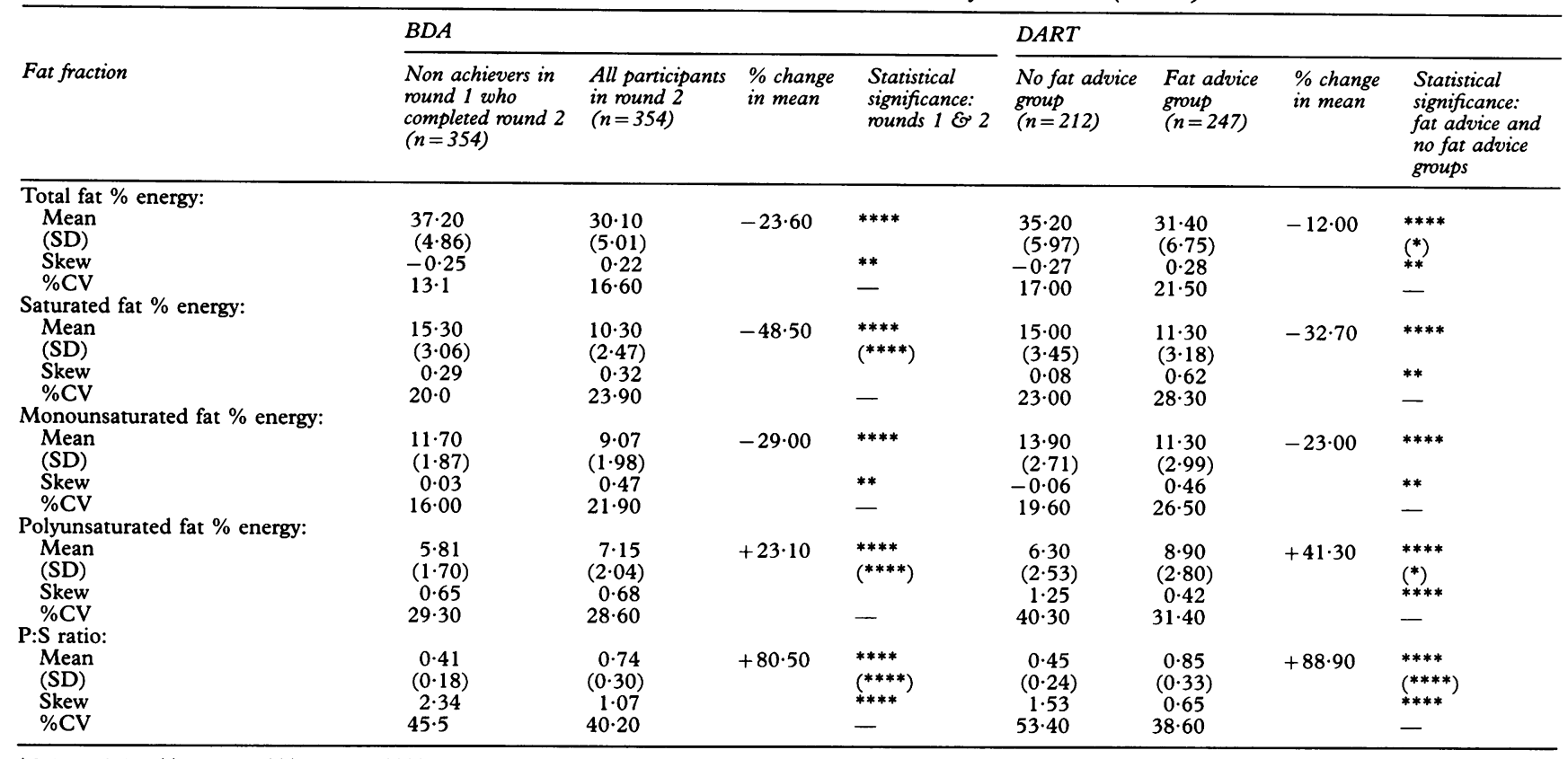

${ }^{*} 0 \cdot 1>\mathrm{p}>0.05 ;{ }^{* *} \mathrm{p}<0.05 ;{ }^{* * *} \mathrm{p}<0.01 ;{ }^{* * * *} \mathrm{p}<0.001 ;$ - statistical test not performed.

The Student's $t$ test, the $F$ test, and the skewness test were used to test for differences in means, SDs, and in skewness respectively between the two groups in the $\mathrm{BDA}$ and DART trials. No statistical test was performed for differences in CV.

the DART trials showed that groups with a lower mean intake were also significantly more positively skewed, had a larger $\mathrm{CV}$, with little change in the SD. The significant shift towards positive skewing at lower mean intakes could again be consistent with a group of high consumers who fail to reduce their intake as the population mean shifts downwards - a "rearguard effect".

For total fat, groups with lower mean intakes had a similar or slightly larger SD and a larger $\mathrm{CV}$ than groups with a high mean intake. At higher mean intakes, the total fat distribution was negatively skewed, consistent with the existence of a group of low consumers. At lower mean intakes the shape of the total fat distribution changed significantly in both trials to become positively skewed. The pattern is similar to that seen for saturates, suggesting a "rearguard effect". The inverse association between the SD and the mean for total fat seems counterintuitive since the SD for saturates and polyunsaturates, which together are the main contributors to total fat, increases with the mean. It remains to be seen whether these latter findings are reproduced when longitudinal population data become available.

CROSS SECTIONAL SURVEYS

Differences between the highest and lowest mean fat fraction intakes across the cross sectional dietary surveys, and for the regionalsocial subgroups of the DNSBA respectively were as follows: $5 \cdot 6 \%$ and $8.5 \%$ for total fat, $14.6 \%$ and $13.5 \%$ for saturates, $34.1 \%$ and $8 \cdot 4 \%$ for monounsaturates, $59 \cdot 1 \%$ and $10 \cdot 1 \%$ for polyunsaturates, and $59 \cdot 2 \%$ and $20.5 \%$ for the P:S ratio (data not shown).

For polyunsaturates and the P:S ratio, differences between the highest and lowest mean intakes across the studies approached those seen in the DART and BDA trials. For polyunsaturates and the P:S ratio there was a positive association between the SDs and the means, and an inverse trend between the coefficients of variation and the means (data not shown). For the cross sectional studies, the correlation coefficient ( $r$ ) between the means and the SDs for polyunsaturates and the P:S ratios respectively were $r=0.86(p<0.01)$ and $r=0.91(p<0.01)$. For the social subgroups of the DNSBA, the correlation coefficient for the means and SDs for polyunsaturates and for the $P: S$ ratios respectively were $r=0.49(0 \cdot 1>p>0.05)$ and $r=0.60 \quad(p<0.05)$. The results from the cross sectional surveys seem to support the results from the DART and BDA trials. Unlike the DART and BDA studies the associations between the skewness statistics and the means were not significant (data not shown).

For total fat, saturates, and monounsaturates, the differences between the highest and lowest mean fat fraction intakes across both the cross sectional surveys and the regional-social subgroups of the DNSBA were far smaller than the differences seen in the BDA and DART trials. Apart from monounsaturates in the cross sectional surveys (where there was a significant positive association between the means and the SDs $(r=0.94 ; p<0.01)$ and an inverse association between the means and skewness statistics $(r=-0.92 ; p<0.01))$, no associations between either the SDs and the means or the skewness statistics and the means were evident (data not shown)

In summary, the analyses from the cross sectional surveys and the regional-social subgroups of the DNSBA confirm the directional trend of association between the mean and the $\mathrm{SD}$, and the mean and the CV, apparent in the 
Table 3 Comparison of constant standard deviation (SD) and constant coefficient of variation $(C V)$ models for saturated fat recommendation, and baseline data*

\begin{tabular}{|c|c|c|c|c|c|}
\hline & \multirow{2}{*}{$\begin{array}{l}\text { Baseline } \\
\text { Mean (SD) }\end{array}$} & \multicolumn{2}{|c|}{ Constant SD model } & \multicolumn{2}{|c|}{ Constant $\mathrm{CV}$ model } \\
\hline & & Mean $(S D)$ & Mean $\pm 2 S D$ & Mean $(S D)$ & Mean $\pm 2 S D$ \\
\hline \multicolumn{6}{|c|}{ Baseline* \% food energy from saturates } \\
\hline Men, $16-64$ y & $16.5(3.0)$ & & & & \\
\hline Women, 16-64 y & $17 \cdot 0(3 \cdot 3)$ & & & & \\
\hline \multicolumn{6}{|c|}{$\begin{array}{l}\text { Possible recommendations for saturates } \\
\text { Mean of } 15 \% \text { : }\end{array}$} \\
\hline Men & & $15 \cdot 0(3.0)$ & $9 \cdot 0-21 \cdot 0$ & $15 \cdot 0(2 \cdot 73)$ & $9 \cdot 5-20 \cdot 5$ \\
\hline Women & & $15 \cdot 0(3 \cdot 3)$ & $8 \cdot 4-21 \cdot 6$ & $15.0(2.91)$ & $9 \cdot 2-20 \cdot 8$ \\
\hline \multicolumn{6}{|l|}{ Mean of $10 \%$ : } \\
\hline Men & & $10 \cdot 0(3 \cdot 0)$ & $4 \cdot 0-16 \cdot 0$ & $10 \cdot 0(1 \cdot 8)$ & $6 \cdot 4-13 \cdot 6$ \\
\hline Women & & $10 \cdot 0(3 \cdot 3)$ & $3 \cdot 4-16 \cdot 6$ & $10.0(1.9)$ & $6 \cdot 1-13 \cdot 9$ \\
\hline \multicolumn{6}{|l|}{ Maximum of $15 \%$ : } \\
\hline Men & & $9 \cdot 0(3 \cdot 0)$ & $3 \cdot 0-15 \cdot 0$ & $11 \cdot 0(2 \cdot 0)$ & $4 \cdot 0-15 \cdot 0$ \\
\hline \multirow{2}{*}{\multicolumn{6}{|c|}{ Maximum of $10 \%$ : }} \\
\hline & & & & & \\
\hline Men & & $4.0(3 \cdot 0)$ & $-2 \cdot 0-10 \cdot 0$ & $7 \cdot 3(1 \cdot 3)$ & $4 \cdot 7-10 \cdot 0$ \\
\hline Women & & $3.4(3.3)$ & $-3 \cdot 2-10 \cdot 0$ & $7 \cdot 2(1 \cdot 4)$ & $4 \cdot 4-10 \cdot 0$ \\
\hline
\end{tabular}

* Dietary and Nutritional Survey of British Adults ${ }^{3}$ when longitudinal population data become available.

SD AND CV

For polyunsaturates and the P:S ratio, the results from both the intervention and the cross sectional studies indicate that the SD is significantly larger and the CV smaller for groups with higher mean intakes. Similarly, for saturates, the intervention studies show that the $S D$ is smaller at lower mean intakes, while the $\mathrm{CV}$ is larger. These two sets of findings are consistent and imply a positive association between the SD and the mean and an inverse association between the $\mathrm{CV}$ and the mean. The results are intermediate between the constant SD model and constant CV model shown in figures 1 and 2 . The constant SD model assumed in the $\mathrm{NACNE}^{4}$ and adopted in the $\mathrm{WHO}^{5}$ dietary goals may therefore be only approximately correct.

Table 3 illustrates differences between both of these models for setting population nutrient goals, using data from the recent DNSBA $^{3}$ as a baseline. For a hypothetical population nutrient goal of a mean of $10 \%$ of energy from saturates, and using the constant SD model, $95 \%$ of the male population would be expected to lie between the values 4.0 and $16.0 \%$ of energy from saturates. Under a constant CV model this range would be narrower $(6.4$ $13 \cdot 6 \%$ ). Alternatively, utilising a maximum value of $15 \%$ of energy as saturates as the target, under the constant SD model the male population mean would be $9.0 \%$, with $95 \%$ of the population lying between the values 3.0 and $15.0 \%$ energy from saturates. Using the constant $\mathrm{CV}$ model, the male population mean would be higher, at $11.0 \%$, and a narrower distribution is produced, with $95 \%$ of the population lying between 4.0 and $15.0 \%$ of energy from saturates.

For total fat and monounsaturates, our analyses of the intervention trials indicate that both the SD and the CV decrease with the mean. These results may imply a large heterogeneity of dietary change in the study groups. It is not clear why this should be observed for these fat fractions but not for saturates and polyunsaturates. Additional data are required to investigate this phenomenon.

important to emphasise that the di intervention trials and the cross sectional dietary surveys essentially address different issues. The intervention trials examined individuals actively changing their diets and hence allow an analysis of change in the shape of the distribution over a period of dietary change, whereas the cross sectional studies allow an examination of the shape of the distribution at different mean intakes. The cross sectional surveys were conducted at different times and in different regions of the UK. The extent of dietary change in the intervention studies was much larger than in the cross sectional surveys and thus more emphasis has been given to the results of the trials. It is important, however, to emphasise that the intervention studies were conducted on highly selected samples. It therefore remains to be seen whether the results obtained can be reproduced

\section{SKEWNESS}

The distributions of polyunsaturates and the dietary P:S ratio exhibit a pattern of skewness suggesting a "vanguard effect". The intervention trials show also a "rearguard effect" in the case of total fat and saturates. These two subgroups may correspond to those who are respectively more and less conscious of healthy eating messages about fat. ${ }^{145}$ It may be that a similar pattern of behaviour would be seen in the general population if repeated dietary surveys were carried out. An analysis of the dietary patterns of those who complied with the COMA 1984 fat recommendations ${ }^{1}$ in the DNSBA will be published elsewhere. ${ }^{23}$

The results of the analyses of the association 
between skewness and the mean supplement other lines of evidence, particularly surveys of attitude and behaviour, ${ }^{24}$ that indicate that the population does not behave homogeneously in response to dietary advice. Certain groups may change more rapidly than others, according to factors such as income, ${ }^{25-27}$ ethnicity, ${ }^{28}$ and culture. ${ }^{29}$ Heterogeneity of dietary behaviours are taken into account in the implementation of dietary goals. ${ }^{30} 31$

With the proviso that no longitudinal population dietary intake data are as yet available, the results reported here provide indirect evidence that the distribution of fat fraction intake may change with the mean to a degree that the setting and monitoring of nutritional goals may need to take account of changes in variance and shape of the intake distribution.

\section{Appendix}

DNSBA SUBGROUPS

These groups included: (i) men aged 16-64 years in northern England in social classes 1, 2 , and 3 non-manual $(\mathrm{n}=111)$; (ii) men aged 16-64 years in northern England in social classes 3 manual, 4 and $5(n=157)$; (iii) women aged 16-64 years in northern England in social classes 1, 2 and 3 non-manual $(n=139)$; (iv) women aged 16-64 years in northern England in social classes 3 manual, 4 and $5(n=148)$; (v) men aged 16-64 years in central and south west England in social classes 1, 2 and 3 nonmanual $(n=148)$; (vi) men aged 16-64 years in central and south west England in social classes 3 manual, 4 and $5(n=187)$; (vii) women aged 16-64 years in central and south west England in social classes 1, 2 and 3 nonmanual $(n=156)$; (viii) women aged 16-64 years in central and south west England in social classes 3 manual, 4 and $5(n=209)$; (ix) men aged 16-64 years in London and the south east in social classes 1,2 and 3 non-manual $(n=186) ;(x)$ men aged 16-64 years in London and the south east in social classes 3 manual, 4 and $5(n=163)$; (xi) women aged 16-64 years in London and the south east in social classes 1, 2 and 3 non-manual ( $n=189$ ); (xii) women aged 16-64 years in London and the south east $(n=160)$. Scotland was excluded due to the small sample size.

Thanks are due to the Department of Health for funding the analyses on which this paper was based, to $M$ Barker, $S$ Bingham I Cole-Hamilton, W Doyle, R Elton, $\mathrm{P}$ Elwood, A Fehily, M Feinleib, K Foster, J Gregory, C Sempos, M Thomson, $M$ Wadsworth for kindly providing the raw data on which analyses were based, to I White for statistical advice, and to $\mathrm{O}$ Al Munderis and N Patel for help with computing.

1 Department of Health and Social Security. Diet and car diovascular disease. London: Committee on Medical Aspects of Food Policy, Report on Health and Social Subjects

2 Cottrell RC. The 1984 COMA report - a new approach Human Nutrition: Applied Nutrition 1985;39A:195-201.
3 Gregory J, Foster K, Tyler H, Wiseman M. The dietary and nutritional survey of British adults. London: OPCS, Socia Survey Division, London: HMSO, 1990.

4 National Advisory Committee on Nutrition Education. $A$ discussion paper on proposals for nutritional guidelines for health education in Britain. London: Health Education Council, 1983

5 World Health Organisation. Diet, nutrition and the prevention of chronic disease. Geneva: WHO, 1990. WHO Technical Report Series no 797.

6 Beaton G, Dietary guidelines: A critical overview. In: Latham MC, Scott van Veen M, eds. Dietary guidelines: proceedings of an international conference. Cornell International Nutrition Monograph Series no 21, 1989; 28-43.

7 National Research Council. Diet and Health. Washington DC: National Academy Press, 1989.

8 Gibney MJ. The disadvantages of quantitative dietary recommendations. Br ₹ Nutr 1990;64:303-4.

9 National Academy Press. Nutrient adequacy assessment usin food consumption surveys. Washington DC: National Academy Press, 1986

10 Burr ML, Fehily AM, Gilbert JF, et al. Effects of changes in fat, fish and fibre intakes on death and myocardial infarction: Diet and reinfarction trial (DART). Lance 1989;ii:757-61.

11 Burr ML, Fehily AM, Rogers S, Welsby E, King S, Sandham $S$. Diet and reinfarction trial (DART): design, recruitment and compliance. Eur Heart $\mathcal{F}$ 1989;10:558-67.

12 Fehily AM, Vaughan-Williams E, Shiels K, et al. The effect of dietary advice on nutrient intakes: evidence from the diet and reinfarction trial (DART). Fournal of Human Nutrition and Dietetics 1989;2:225-35.

13 Cole-Hamilton I, Gunner K, Leverkus C, Starr J. A study among dietitians and adult members of their households of the practicalities and implications of following proposed dietary guidelines for the UK. Human Nutrition: Applied Nutrition 1986;40A:365-89.

14 Barker ME, McClean SI, McKenna PG, et al. Diet, lifestyle and health in Northern Ireland. Coleraine: Centre for Applied Health Studies, University of Ulster at Coleraine, plied 1989.

15 Logan RL, Riemersma RA, Thomson M, et al. Risk factors for ischaemic heart disease in normal men aged 40 years, Edinburgh-Stockholm study. Lancet 1978;ii:949-54

16 Thomson M, Logan RL, Sharman M, Lockerbie L, Riemersma RA, Oliver MF. Dietary survey in 40 year old Edinburgh men. Human Nutrition: Applied Nutrition 1982 36A: 272-80.

17 Wood DA, Butler S, Riemersma RA, et al. Adipose tissue and platelet fatty acids and coronary heart disease in Scottish men. Lancet 1984;i:117-21.

18 Fehily AM, Phillips KM, Sweetnam PM. A weighed dietary survey of men in Caerphilly, South Wales. Human $\mathrm{Nu}$ trition: Applied Nutrition 1984;38A:270-6.

19 MRC Epidemiology Unit. The Caerphilly and Speedwell collaborative heart disease studies. Progress report VI, results from the prevalence studies. Cardiff: MRC Epidemiology Unit, 1988 .

20 Snedecor GW, Cochran WG. Statistical methods. Ames: Iowa State University Press, 1967.

21 Paul AA, Southgate DAT. McCance and Widdowson's the composition of foods. London: HMSO, 1978.

22 Report of the Panel on Dietary Reference Values of the Committee on Medical Aspects of Food Policy. Dietary Reference Values for Food Energy and Nutrients for the United Kingdom. London: Department of Health Report on Health and Social Subjects no 41, 1991.

23 Pryer J, Dimond H, Brunner E, Marmot M, Elliott P. Who complies with dietary recommendations for the prevention of coronary heart disease and what do they eat? Finding from a UK study. Circulation 1992;85:A9.

24 Cox BD, Blaxter M, Buckle ALJ, et al. The health and lifestyle survey. London: Health Promotion Research Trust, 1987.

25 Cole-Hamilton I, Lang T. Tightening belts: a report on the impact of poverty on food. London: London Food Commission, 1986

26 Brunner EJ. Heart disease prevention .... and money. THS Health Summary 1987;4(5):6.

27 Dowler E. Diet and coronary heart disease in women potential policy implications. Food Policy 1993;ii:224-36. 28 McKeigue PM, Marmot MG, Adelstein AM, et al. Dietary risk factors for coronary heart disease in Asians in northrisk factors for coronary heart disease

29 Davison C, Frankel S, Davey Smith G. The limits of lifestyle: Re-assessing "fatalism" in the popular culture of illness Re-assessing "fatalism" in the popular cultu

30 walker CL, Robbins C, Samderson ME, Wadsworth JP. Implementing the NACNE report. Lancet 1983;ii:135156.

31 Look After Your Heart Programme. Beating heart disease in the 1990s: a strategy for 1990-95. London: Health Education Authority, 1990 